\title{
STUDI ALTERNATIF BANGUNAN PENGAMAN PANTAI DI PESISIR KABUPATEN KARAWANG
}

\author{
ALTERNATIVE STUDY OF SHORE PROTECTION STRUCTURES \\ IN KARAWANG REGENCY
}

\author{
Roberto Pasaribu $^{1 *}$, Asep Irwan ${ }^{2}$, Liliek Soeprijadi ${ }^{1}$, Chrisoetanto Pattirane ${ }^{1}$ \\ ${ }^{1}$ Politeknik Kelautan dan Perikanan Karawang, Jalan Lingkar Tanjungpura, Karangpawitan, Kecamatan \\ Karawang Barat, Kabupaten Karawang, Jawa Barat 41315 \\ ${ }^{2}$ Program Studi Teknik Sipil, Institut Teknologi dan Sains Bandung, Kota Deltamas Lot-Al CBD, \\ Jl. Ganesha Boulevard, Pasirranji, Kec. Cikarang Pusat, Bekasi, Jawa Barat 17530
}

Teregistrasi I tanggal: 07 April 2020; Diterima setelah perbaikan tanggal: 23 Mei 2020; Disetujui terbit tanggal: 24 Mei 2020

\begin{abstract}
ABSTRAK
Dinamika oseanografi pantai Karawang sangat dipengaruhi oleh gelombang dari Laut Jawa. Proses hidro-oseanografi ini menyebabkan kerusakan di beberapa tempat di Pantai Utara Karawang. Penyebab kerusakan yang paling utama adalah gelombang laut yang datang dari arah timur laut. Gelombang ini menyebabkan adanya arus sejajar pantai dan tegak lurus pantai yang menyebabkan terjadinya abrasi dan sedimentasi pantai. Kerusakan pantai dapat dicegah dengan mendirikan bangunan pengaman pantai. Penelitian ini bertujuan untuk menentukan jenis bangunan pengaman pantai sebagai salah satu cara mencegah kerusakan pantai di pesisir kabupaten Karawang dengan cara mengumpulkan, mengolah dan menganalisis data batimetri, angin dan pasang surut. Berdasarkan analisis data pasang surut dapat menentukan elevasi bangunan, dari pengolahan data angin diperoleh peramalan gelombang berupa tinggi, periode, dan arah gelombang. Hasil analisis gelombang, batimetri dan topografi, diperoleh bahwa jenis bangunan pantai yang sesuai untuk pengaman pantai di pesisir kabupaten Karawang adalah bangunan breakwater dan groin. Breakwater dan groin dipilih untuk pengaman pantai di pantai Karawang karena dapat mengurangi limpasan gelombang yang terjadi, sehingga dapat melindungi pantai dari gempuran gelombang supaya tidak terjadi abrasi.
\end{abstract}

Kata kunci: bangunan pantai, abrasi, sedimentasi, breakwater, groin

\section{ABSTRACT}

The oceanographic dynamics of Karawang Beach, located on the north coast, are strongly influenced by waves from the Java Sea. This hydro-oceanography process caused damage in several places on the Karawang North Coast. The main cause of damage is the sea waves from the northeast The dynamics of Karawang Beach are strongly influenced by waves from the Java Sea which lie north of the coast. This hydro-oceanographic process caused damage to several places on the north coast of Karawang. The main cause of damage is the sea waves from the northeast direction. This wave causes the current parallel to the coast and perpendicular to the coast which causes abrasion and sedimentation of the coast. Damage to the beach can be prevented by erecting coastal security structures. This study aims to determine the type of coastal security structures as a way to prevent damage to beaches in the Karawang regency coast by collecting, processing and analyzing bathymetry, wind and tidal data. From tidal data analysis can determine the building

Korespondensi penulis:

*Email: roberto_pasa@yahoo.com

DOI: http://dx.doi.org/10.15578/plgc.v1i2.8875 
elevation, from the processing of wind data obtained by wave forecasting in the form of height, period, and wave direction. From the results of wave, bathymetry and topographic analysis, the type of beach structure suitable for coastal protection in the Karawang regency is the Breakwater and Groin buildings. Breakwater and Groin were chosen for coastal protection in Karawang Beach because it can reduce wave runoff that occurs, so as to protect the coast from the waves so that no abrasion occurs.

Keywords: Shore Protection Structures, abrasion, sedimentation, breakwater, groynes

\section{PENDAHULUAN}

Pantai Karawang merupakan salah satu tempat untuk berwisata bagi penduduk lokal karena mempunyai pantai yang indah, namun dari hasil pengamatan pada lokasi di pantai tersebut sering terjadi erosi akibat dari himpasan gelombang laut dan transport sedimen. Erosi yang terjadi di pantai Karawang mengakibatkan adanya perubahan fisik yaitu kemunduran garis pantai dan juga ganguan terhadap aktivitas masyarakat yang tinggal di sekitar pantai. Menurut (Pasaribu et al. (2019) dan Agus et al. (2020), pantai utara kabupaten Karawang telah mengalami perubahan garis pantai. Kondisi tersebut tentunya membutuhkan penanganan yang khusus yaitu dengan membuat bangunan pengaman pantai (groin, jetty, revetment, seawall, breakwater), untuk itu perlu suatu pemahaman dan ketelitian yang mendalam dalam pemilihan pengaman pantai yang sesuai.

Pemilihan pengaman pantai yang sesuai tentunya akan sangat membantu untuk mencegah dan meminimalisir kemungkinan terjadinya abrasi dan erosi yang lebih besar pada daerah pantai akibat diterjang gelombang. Pemilihan pengaman pantai yang sesuai dan desain yang tepat pada bangunan pengaman pantai adalah suatu hal yang sangat diperlukan sesuai dengan kebutuhan daerah kawasan pantai tersebut.

Untuk melindungi pantai dari kerusakan yang diakibatkan abrasi dilakukan dengan cara membuat bangunan pantai. Bangunan pantai adalah segala jenis infrastruktur yang dibangun di garis pantai dan dapat berfungsi sebagai pelindung pantai dan darat atau pelabuhan. Secara sederhana, bangunan pantai adalah infrastuktur yang di desain khusus di pantai untuk segala jenis aktivitas. Bangunan ini berfungsi untuk mengurangi besarnya gelombang yang sampai di pantai (Pratikto et al., 2014). Dalam pemilihan alternatif bangunan pantai yang akan diambil untuk menanggulangi abrasi pada pantai Karawang perlu dipertimbangkan berbagai faktor yang mempengaruhi abrasi pada pantai dan tujuan yang akan dicapai serta pengaruh terhadap lingkungan. Berbagai faktor tersebut harus dipertimbangkan secara matang agar solusi yang diambil benarbenar efektif untuk menanggulangi abrasi di pantai Karawang. Penelitian ini bertujuan menentukan jenis bangunan pengaman pantai yang sesuai untuk dibangun di kawasan pantai Kabupaten Karawang.

\section{BAHAN DAN METODE}

Lokasi dan Waktu Penelitian

Penelitian dilaksanakan di beberapa desa sepanjang garis pantai di Kabupaten Karawang. Kabupaten Karawang berada di bagian utara Provinsi Jawa Barat yang secara geografis terletak antara $107^{\circ} 02^{\prime}$ $107^{\circ} 40^{\prime}$ BT dan $05^{\circ} 56^{\prime}-06^{\circ} 34^{\prime}$ LS. 


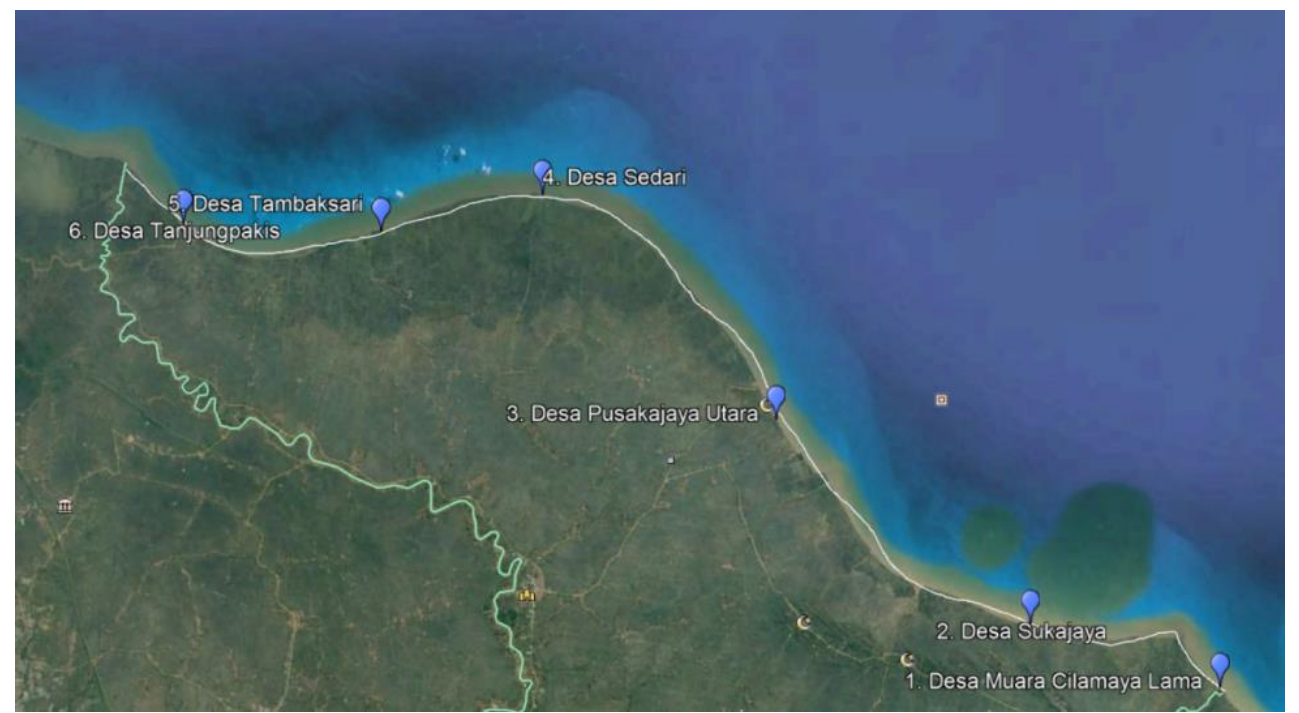

Gambar 1. Lokasi Penelitian

Figure 1. Research Location

Pengamatan data primer dilakukan di 6 lokasi kecamatan yang tersebar disepanjang pantai Karawang yaitu sepanjang pantai desa Muara Cilamaya Lama, desa Sukajaya, desa Pusakajaya Utara, desa Sedari, desa Tambaksari, dan desa Tanjungpakis. Penelitian ini dilakukan pada bulan Juli sampai dengan Nopember 2019.

\section{Alat dan Bahan}

Peralatan yang digunakan bertujuan untuk melihat kondisi pesisir pantai utara kabupaten Karawang. Peralatan tersebut dapat dilihat pada Tabel 1 .

\section{Pengumpulan Data}

Data yang digunakan ada 2 jenis, yaitu data primer data dan sekunder. Data primer adalah survey langsung ke lapangan untuk mengukur data hidrooseanografi sesaat dan melakukan pengamatan kondisi pantai sedangkan data sekunder adalah data yang melengkapi data primer dalam menganalisa data. Data sekunder antara lain peta wilayah pesisir kabupaten Karawang, data topografi, batimetri, gelombang, arus, data pasang surut dan data angin, seperti Tabel 2.

Tabel 1. Alat Penelitian

Table 1. Research tools

\begin{tabular}{|c|c|c|c|}
\hline No. & Alat dan Bahan & Spesifikasi Alat & Kegunaan \\
\hline 1. & GPS Handheld & Garmin & Menenentukan posisi penelitian \\
\hline 2. & Waterpass & Topcon & $\begin{array}{l}\text { Menentukan keseimbangan } \\
\text { pengukuran }\end{array}$ \\
\hline 3. & Tripod & - & \\
\hline 4. & Kamera & - & Membuat dokumentasi \\
\hline 5. & Palm Pasut & - & Menentukan tinggi Pasut \\
\hline 6. & Roll Meter & - & Mengukur Jarak \\
\hline 7. & Perangkat Lunak GENESIS & CEDAS 2.01 & Mengolah data gelombang \\
\hline 8. & Perangkat Lunak WRPLOT & $\begin{array}{l}\text { Lakes } \quad \text { Environmental } \\
\text { V.8.0.2 }\end{array}$ & Mengolah data gelombang \\
\hline
\end{tabular}


Tabel 2. Data primer dan sekunder

Table 2. Primary and secondary data

\begin{tabular}{lll}
\hline No. & Data & Sumber Data \\
\hline 1. & Peta Batimetri & GEBCO (www.gebco.net) \\
2. & Data Pasang Surut & BIG (http://tides.big.go.id/) \\
3. & Data Angin 10 Tahun & ECMWF (https://www.ecmwf.int/) \\
4. & Data Garis Pantai & Google Earth (Citra Satelit) \\
5. & Informasi Lapangan & Kondisi Pantai (Primer) \\
\hline
\end{tabular}

\section{a. Data topografi dan batimetri}

Data Topografi yang digunakan berdasarkan data Digital Elevation (DEM) yang diperoleh dari Badan Informasi Geospasial. DEM Nasional dibangun dari beberapa sumber data meliputi data IFSAR (resolusi 5m), TERRASAR-X (resolusi 5m) dan ALOS PALSAR (resolusi $11.25 \mathrm{~m}$ ), dengan menambahkan data Masspoint hasil stereo-plotting. Resolusi spasial DEMNAS adalah 0.27arcsecond, dengan menggunakan datum vertikal EGM2008.

\section{b. Data Pasang Surut}

Data Pasang Surut didapatkan secara sekunder dan pengukuran sesaat selama pengamatan di lapangan. Data skunder yang diperoleh dari Badan Informasi Geospasial yang tersaji di website resmi yaitu http://tides.big.go.id/pasut/.

\section{c. Data angin dan gelombang}

Data gelombang yang diperoleh adalah dengan melakukan peramalan/prediksi gelombang. Salah satu cara peramalan gelombang adalah dengan melakukan pengolahan data angin. Prediksi gelombang yang dihitung berdasarkan kondisi meteorologi yang telah lampau disebut hindcasting. Data angin diperoleh dari ECMWF (European Centre for Medium-Range Weather Forecasts) pada lokasi Perairan Bahumbelu dengan rentang waktu 10 Tahun mulai dari 2009 hingga 2018 (Irwan, 2019). Untuk mendapatkan gelombang rencana, dilakukan peramalan gelombang berdasarkan data angin jangka panjang. Metode yang diterapkan mengikuti metode yang ada di Shore Protection Manual (CERC, 1984).

\section{Metode Analisis Data}

Langkah pertama dalam melakukan analisis dan pemodelan garis pantai adalah melakukan pemodelan transformasi gelombang. Untuk keperluan analisis ini digunakan model STWAVE (STeadystate spectral WAVE). Baik model STWAVE maupun GENESIS keduanya berada dalam satu perangkat lunak CEDAS (Coastal Engineering Design \& Analysis System) yang dikembangkan oleh U.S. Army Corps of Engineers' Engineering Research and Development Center (CERC, 2020; Hariyadi, 2011). Dalam pemodelan gelombang dibutuhkan beberapa data masukan, seperti topografi, data batimetri, pasang surut, arus dan data tanah, dalam penelitian ini data batimetri, pasang surut dan arus mengunakan data sekunder.

\section{HASIL DAN BAHASAN HASIL}

\section{Kondisi Batimetri}

Data batimeri didapatkan dari General Bathymetric Chart of the Oceans (GEBCO) yang menyajikan data batimetri secara global, kemudian data GEBCO tersebut disajikan pada perangkat GENESIS sebagai input proses model garis pantai (Gambar 2). 

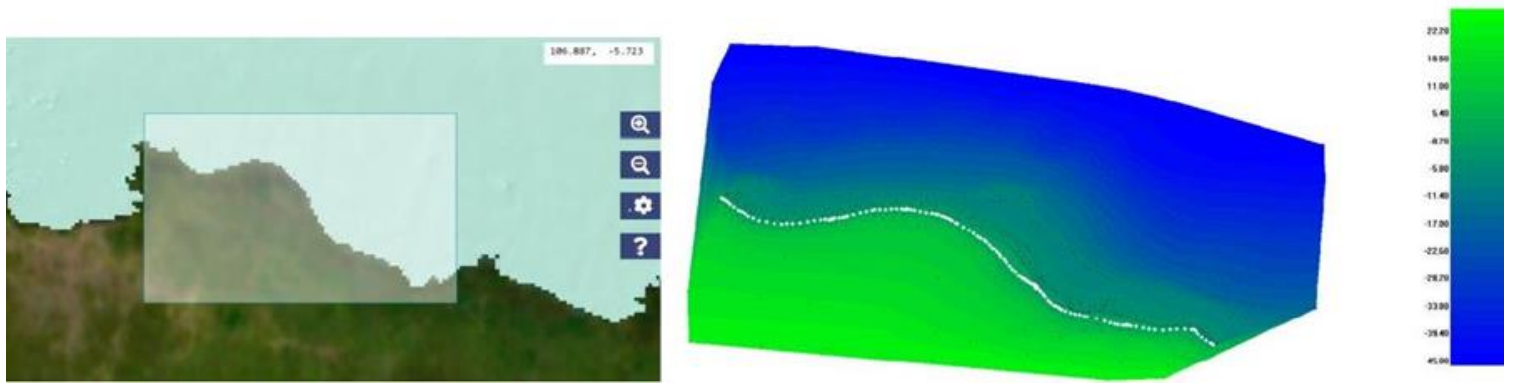

(Sumber: GEBCO, 2019)

Gambar 2. Batimetri dan Model Garis Pantai Kab. Karawang Figure 2. Bathymetry and Coastline Model in Karawang Regency

Berdasarkan hasil pengambilan data batimetri variasi kedalaman di sekitar garis pantai Kabupaten Karawang (garis putih) yaitu antara -5 sampai dengan -17 meter, artinya kondisi batimetri di pantai Karawang cenderung landai.

\section{Kondisi Pasang Surut}

Data pasang surut didapatkan dari stasiun Badan Informasi Geospasial (BIG) terdekat kemudian dikalibrasikan dengan pengamatan lapangan pada rentang waktu selama 3 jam, dengan grafik pasut sesuai Gambar 3.

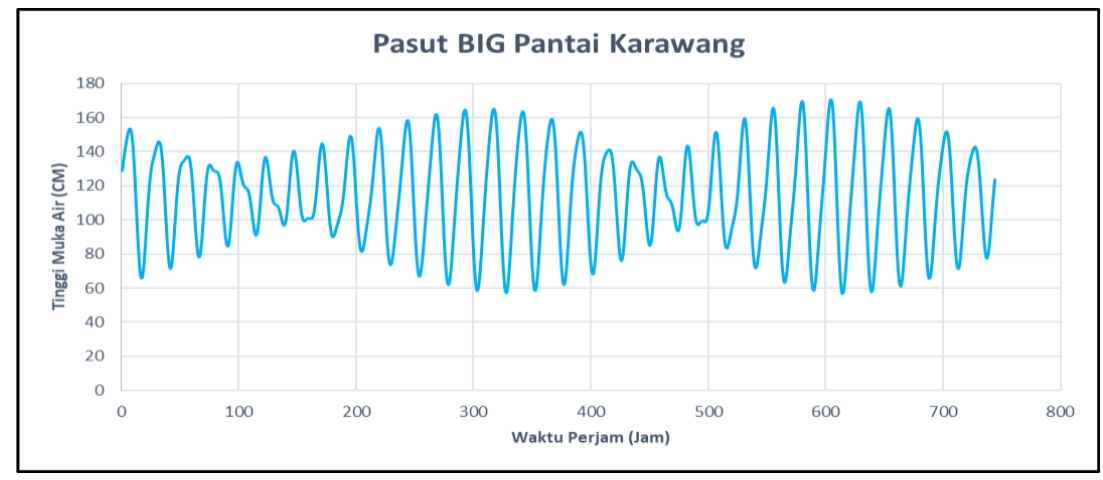

Gambar 3. Grafik Pasut Pantai Karawang- Data BIG Bulan Desember thn 2019 Figure 3. Tidal Graph on Karawang Beach in December 2019

Hasil pengolahan data pasang surut dengan menggunakan Least Square, didapatkan konstanta harmonik sehingga dapat dihitung nilai Mean Sea Level (MSL), Mean High Water Spring (MHWS), Mean Highest Water Level (MHWL), Mean Low Water Spring
(MLWS), Mean Low Water Level (MHWL) dan muka air rerata yang diukur dari Datum LWS (Z0). Hasil dari analisis pasang surut tersebut berupa hasil perhitungan sembilan (9) konstanta harmonik dengan menggunakan metode Least Square sesuai Tabel 3.

Tabel 3. Konstanta Harmonik Pasang Surut Table 3. Tidal Harmonics Constant

\begin{tabular}{lllllllllll}
\hline & So & M2 & S2 & N2 & K2 & K1 & O1 & P1 & M4 & MS4 \\
\hline A cm & 114.02 & 8.34 & 2.67 & 1.25 & 2.27 & 24.96 & 17.37 & 11.98 & 0.01 & 0.01 \\
G & & 81.61 & 103.14 & 22.1 & 102.78 & -13.36 & 0.8 & 148.52 & 246.23 & 73.26 \\
\hline
\end{tabular}


Dengan menggunakan Tabel 3, dihitung nilai bilangan Formzahl dan diperoleh $\mathrm{F}=3.84$ yang menunjukkan bahwa perairan Pantai Karawang memiliki jenis/tipe pasang surut harian tunggal, dengan nilai tunggang pasang surut berdasarkan analisis dengan metode Least Square adalah 1.22 meter. Hasil pengukuran hidrografi/batimetri harus mengacu pada suatu bidang persamaan atau datum, sebagai acuan untuk pekerjaan rekayasa pantai. Elevasi penting yang dihasilkan dari analisis pasang surut dengan metode Least Square sesuai Tabel 4.

Tabel 4. Nilai Pasang Surut Metode Least Square di Pantai Karawang, tahun 2019

Table 4. Tidal Value Least Square Method in the coastal of the Karawang Regency in 2019

\begin{tabular}{llll}
\hline Jenis Elevasi & & 29 piantan $(\mathrm{m})$ & DATUM $(\mathrm{m})$ \\
\hline Highest High SPRING & (HWS) & 1.73 & 1.22 \\
Mean High Water Spring & (MHWS) & 1.60 & 1.09 \\
Mean Sea Level & (MSL) & 1.14 & 0.63 \\
Mean Low Water Spring & (MLWS) & 0.64 & 0.13 \\
Lowest Water SPRING & (LWS) & 0.51 & 0 \\
Tunggang Pasut (HWS-LWS) & & 1.22 & \\
Z0 (MSL-LWS) & & 0.63 & \\
\hline
\end{tabular}

Data pasang surut hasil pengolahan kemudian dikalibrasikan dengan data pengamatan lapangan dan diperoleh hasil sesuai grafik pada Gambar 4. Data pengamatan tidak jauh berbeda dengan data hasil pengolahan yang diperoleh dari Badan Informasi Geospasial, dengan nilai tunggang pasut sebesar 1.22 meter.

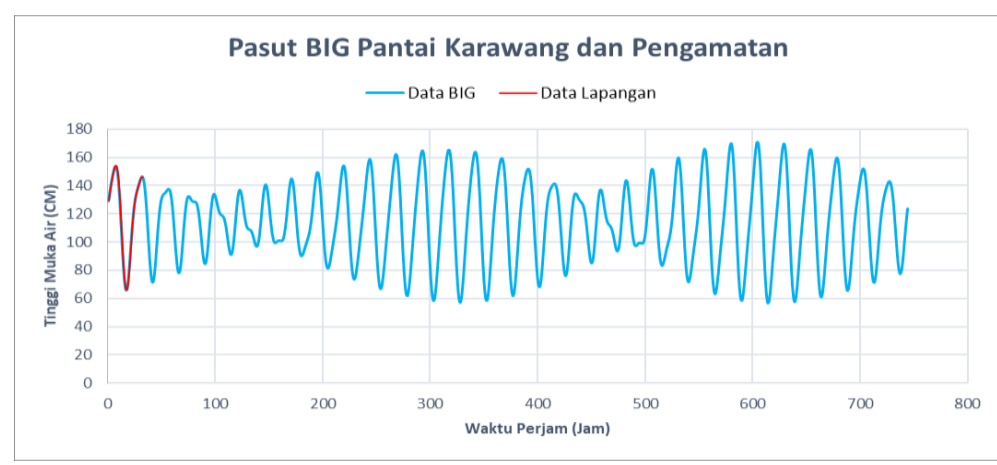

Gambar 4. Grafik hasil kalibrasi pasang surut BIG dan pengamatan Figure 4. Graph of BIG tidal calibration results and observations

\section{Kondisi Gelombang}

Data angin digunakan sebagai data masukan perhitungan tinggi gelombang yang terjadi di lokasi kajian. Data angin yang digunakan adalah data angin dari European Centre for Medium-Range Weather Forecasts (ECMWF). Dalam penelitian ini digunakan data angin dengan rentang waktu 10 tahun (20062015) sesuai Gambar 5. Selanjutnya arah angin di lokasi penelitian digambarkan dalam sebuah diagram mawar angin (windrose) sesuai Gambar 6.

Berdasarkan data angin 10 tahun mulai dari tahun 2006 sampai dengan 2015 sesuai Tabel 5, didapatkan arah dan kecepatan dominansi angin pada lokasi penelitian yaitu dari Timur sebesar 27\% serta dari arah Tenggara sebesar $20 \%$. Kecepatan angin pada lokasi penelitian berkisar rata-rata $4.8 \mathrm{~m} / \mathrm{s}$, dimana kejadian 
angin terbesar dari arah Timur dan Tenggara. Gelombang di laut dianggap akibat dari gesekan angin permukaan yang dapat membangkitkan gelombang sampai menuju lokasi penelitian. Berdasarkan windrose, dapat dilihat bahwa di lokasi penelitian, sepanjang pantai Karawang angin dominan bertiup dari arah timur sepanjang tahun, kemudian diikuti dari arah barat, timur laut, dan utara yang terjadi pada musim barat yaitu Desember sampai dengan Maret.

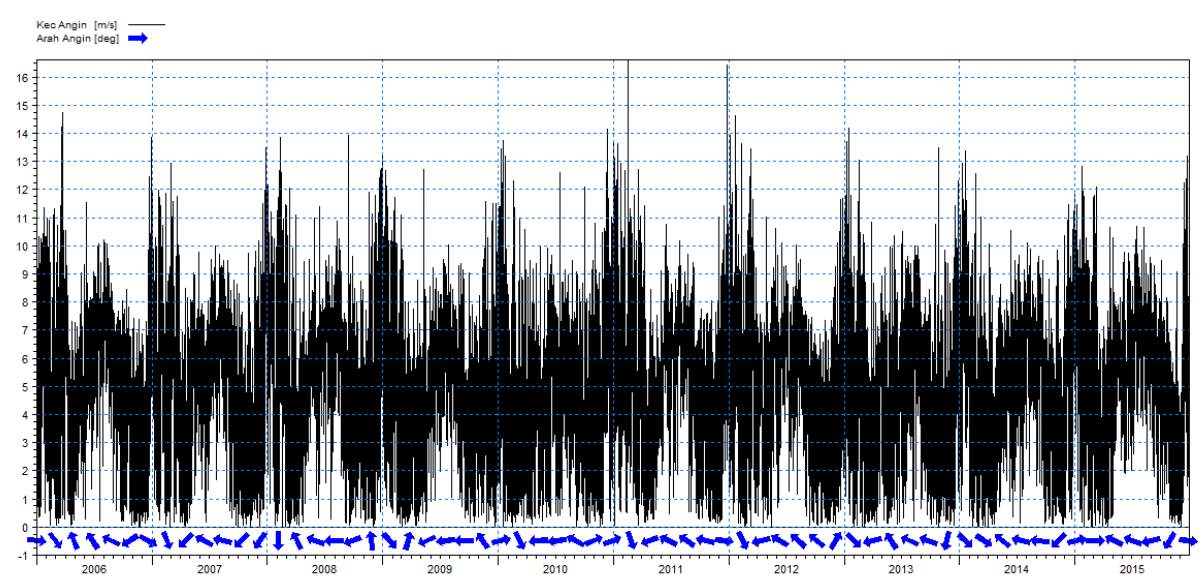

(Sumber: ECMWF, 2019)

Gambar 5. Data Angin disekitar pantai Karawang 10 Tahun (2006-2015) Figure 5. Wind data around the Karawang coast in 10 years (2006-2015)

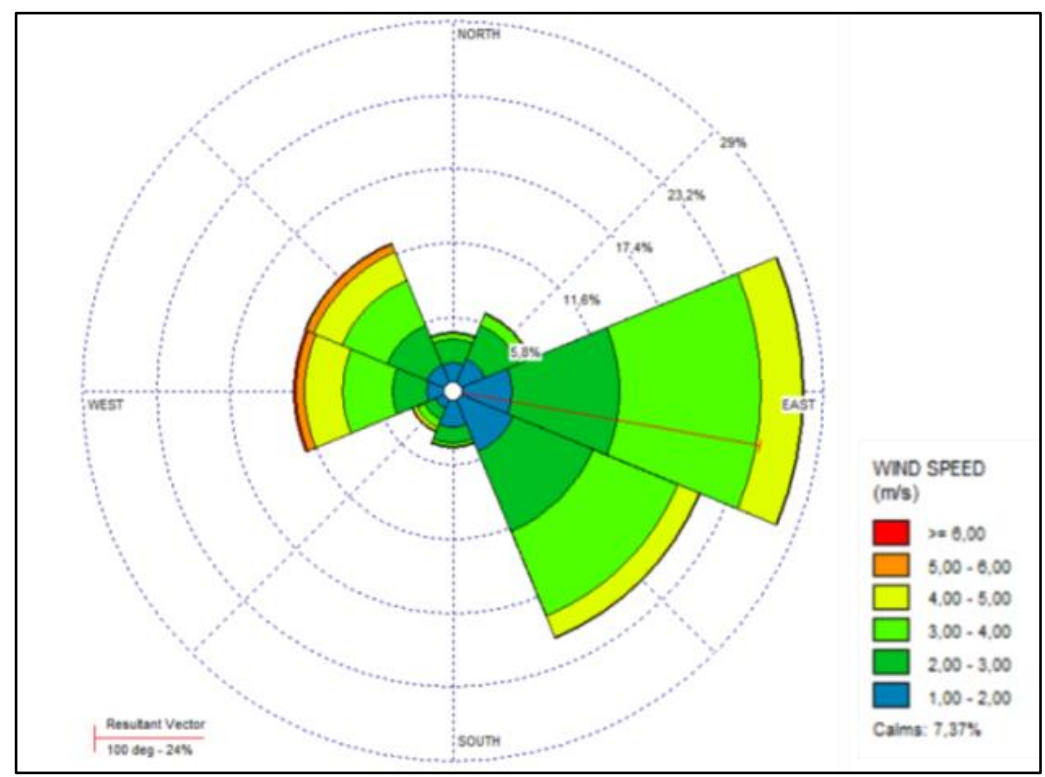

(Sumber: ECMWF, 2019)

Gambar 6. Windrose 10 Tahun (2006-2015)

Figure 6. Windrose in 10 years (2006-2015) 
Studi alternatif bangunan ...... kabupaten Karawang (Pasaribu R, et al)

Tabel 5. Distribusi Frequency Angin 10 Tahun (2006-2015)

Table 5. Distribution of wind frequency in 10 years (2006-2015)

\begin{tabular}{|c|c|c|c|c|c|c|c|}
\hline \multirow{2}{*}{ Directions } & \multicolumn{6}{|c|}{ Wind Classes (m/s) Frequency Distribution } & \multirow{2}{*}{ Total (\%) } \\
\hline & $1,00-2,00$ & $2,00-3,00$ & $3,00-4,00$ & $4,00-5,00$ & $5,00-6,00$ & $>=6,00$ & \\
\hline $\mathrm{N}$ & 0,02274 & 0,01819 & 0,00476 & 0,00109 & 0,00024 & 0,00000 & 0,04701 \\
\hline $\mathrm{NE}$ & 0,02732 & 0,02878 & 0,00938 & 0,00054 & 0,00006 & 0,00002 & 0,06610 \\
\hline $\mathrm{E}$ & 0,04680 & 0,08316 & 0,11062 & 0,03220 & 0,00119 & 0,00006 & 0,27403 \\
\hline SE & 0,05146 & 0,06729 & 0,07089 & 0,01891 & 0,00076 & 0,00000 & 0,20931 \\
\hline $\mathrm{S}$ & 0,02834 & 0,01209 & 0,00358 & 0,00090 & 0,00017 & 0,00001 & 0,04509 \\
\hline SW & 0,01534 & 0,00948 & 0,00607 & 0,00315 & 0,00064 & 0,00010 & 0,03477 \\
\hline$W$ & 0,02057 & 0,02656 & 0,03932 & 0,02933 & 0,00649 & 0,00197 & 0,12424 \\
\hline NW & 0,02331 & 0,03299 & 0,03825 & 0,02308 & 0,00700 & 0,00111 & 0,12573 \\
\hline Sub-Total & 0,23587 & 0,27853 & 0,28286 & 0,10920 & 0,01655 & 0,00327 & 0,92628 \\
\hline Calms & & & & & & & 0,07372 \\
\hline Total & & & & & & & 1,00 \\
\hline
\end{tabular}

\section{Peramalan Gelombang Perairan Dalam}

Untuk melakukan peramalan gelombang di suatu perairan diperlukan masukan berupa data angin dan peta batimetri. Peta perairan lokasi dan sekitarnya diperlukan untuk menentukan besarnya "fetch" atau kawasan pembentukan gelombang. Fetch adalah daerah pembentukan gelombang yang diasumsikan memiliki kecepatan dan arah angin yang relatif konstan. Adanya kenyataan bahwa angin bertiup dalam arah yang bervariasi atau sembarang, maka panjang fetch diukur dari titik pengamatan dengan interval $5^{\circ}$.

Jumlah pengukuran fetch untuk tiap arah mata angin tersebut meliputi pengukuran-pengukuran dalam wilayah pengaruh fetch $\left(22,5^{\circ}\right.$ searah jarum jam dan $22,5^{\circ}$ berlawanan arah jarum jam dari masing-masing arah mata angin). Hasil perhitungan fetch efektif pada lokasi penelitian disajikan pada Gambar 7.

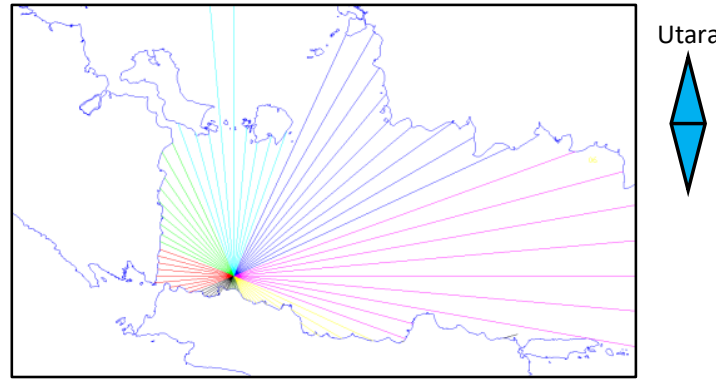

Gambar 7. Fetch Perairan Terluar Kabupaten Karawang

Figure 7. Map of Fetch Outermost Waters of Karawang Regency

Berdasarkan waverose selama 10 tahun (Gambar 8), pada lokasi kajian diperoleh dominasi gelombang dari arah Timur dengan tinggi gelombang antara 30 $\mathrm{cm}$ sampai dengan lebih dari $150 \mathrm{~cm}$. Arah dan tinggi gelombang pada lokasi penelitian didominansi dari arah Timur (25\%) serta Barat Laut (10\%). Tinggi Gelombang pada lokasi penelitian berkisar rata-rata $0.98 \mathrm{~m}$, dimana kejadian gelombang terbesar dari arah Timur dan Barat Laut. 


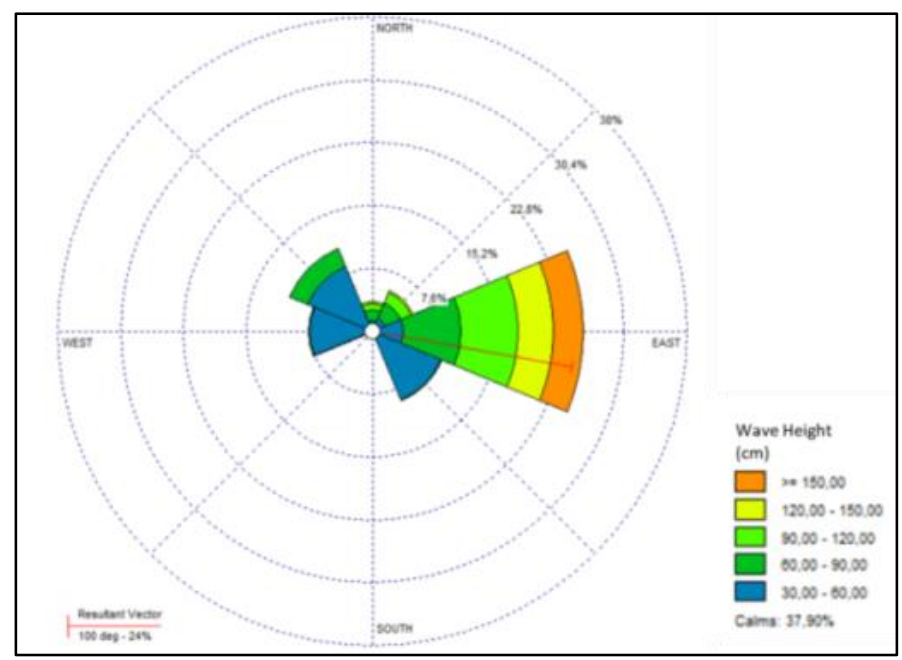

Gambar 8. Waverose Tinggi Gelombang di lokasi penelitian (2006-2015)

Figure 8. Waverose of High Wave Waters of Karawang Regency (2006-2015)

\section{Jenis Bangunan Pengaman Pantai}

Pemilihan bangunan pengaman pantai yang sesuai tentunya akan sangat membantu untuk mencegah dan meminimalisir kemungkinan terjadi adanya abrasi dan erosi yang lebih besar pada daerah pantai akibat diterjang gelombang. Sesuai dengan fungsinya, bangunan pantai dibedakan dalam tiga kelompok yaitu: konstruksi yang dibangun di pantai dan sejajar dengan garis pantai (contoh: revetment), konstruksi yang dibangun tegak lurus garis pantai (contoh: groin dan jetty) dan konstruksi yang dibangun di lepas pantai dan sejajar dengan garis pantai (contoh breakwater).

Pada pemilihan alternatif bangunan pengaman pantai yang direncanakan dipertimbangkan faktor yang mempengaruhi abrasi pada pantai dan tujuan yang akan dicapai serta pengaruh terhadap lingkungan. Faktor-faktor yang harus dipertimbangkan adalah arah gelombang laut, batimetri, pasang surut, dan jarak bangunan dari garis pantai. Berdasarkan faktor-faktor diatas maka dapat ditentukan jenis bangunan pantai yang sesuai dengan lokasi penelitian, yaitu:

\section{a. Desa Muara Cilamaya Lama}

Gelombang yang datang ke pantai ini berasal dari Timur Laut dan Timur serta kondisi batimetri yang landai dan garis pantai yang berubah akibat sedimentasi, maka bangunan pantai yang sesuai pada lokasi ini adalah bangunan Jetty pada muara sungai.

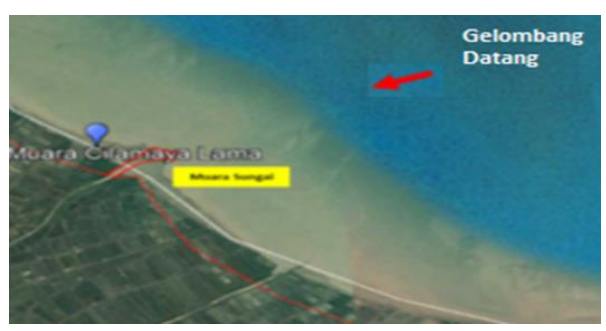

Gambar 9. Lokasi bangunan Jetty di desa Muara Cilamaya Lama

Figure 9. Location of the Jetty building in Muara Cilamaya Lama village

\section{b. Desa Sukajaya}

Gelombang yang datang ke pantai ini berasal dari Timur Laut dan Timur dimana arahnya tidak tegak lurus serta kondisi batimetri yang landai dan bentuk garis pantai yang merubah akibat abrasi maka bangunan pelindung yang cocok adalah bangunan groin.

\section{c. Desa Pusakajaya Utara}

Gelombang yang datang ke pantai ini berasal dari Timur Laut dan Timur dimana arah nya tegak lurus pantai serta kondisi batimetri yang landai dan garis pantai yang berubah akibat abrasi maka 
bangunan pelindung yang cocok adalah bangunan breakwater.

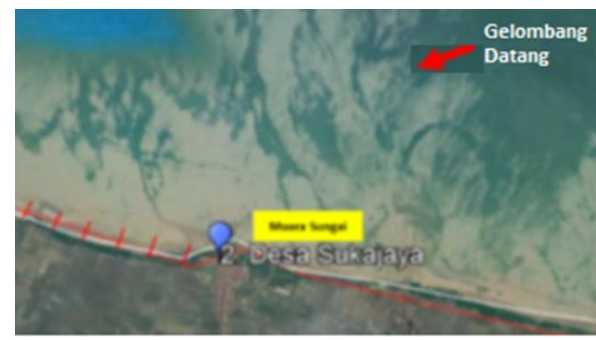

Gambar 10. Lokasi bangunan Groin di desa Sukajaya

Figure 10. Location of the Groin building in Sukajaya village

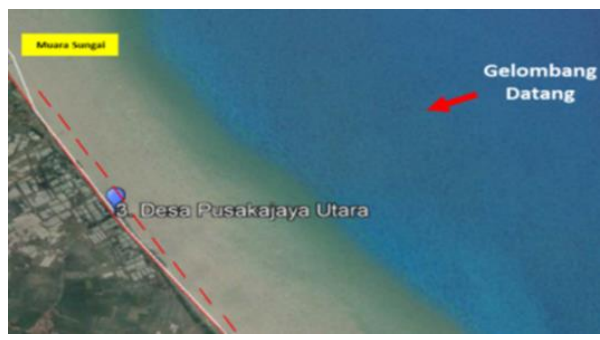

Gambar 11. Lokasi bangunan Breakwater di Desa Pusakajaya Utara

Figure 11. Location of the Breakwater building in Pusakajaya Utara village

\section{d. Desa Sedari}

Gelombang yang datang ke pantai ini berasal dari Timur Laut dan Timur serta arah nya tidak tegak lurus pantai serta kondisi batimetri yang landai dan bentuk garis pantai yang merubah akibat abrasi maka bangunan pelindung yang cocok adalah bangunan groin.

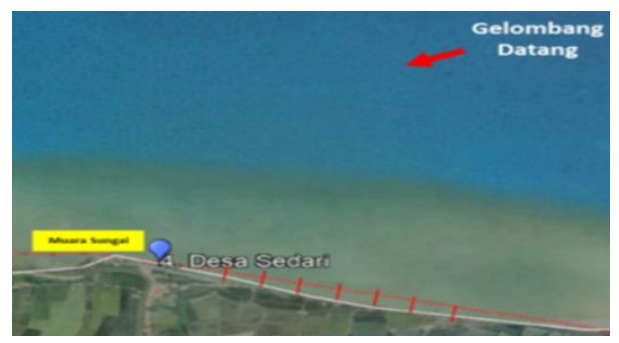

Gambar 12. Lokasi bangunan Groin di Desa Sedari

Figure 12. Location of the groin building in Sedari village

\section{e. Desa Tambaksari}

Gelombang yang datang ke pantai ini berasal dari Timur Laut dan Timur serta arah nya tidak tegak lurus pantai serta kondisi batimetri yang landai dan bentuk garis pantai yang merubah akibat abrasi maka bangunan pelindung yang cocok adalah bangunan groin.

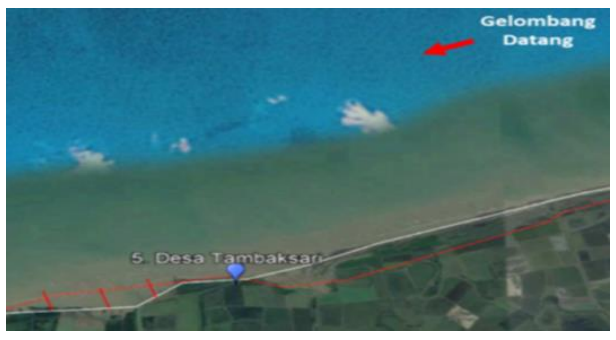

Gambar 13. Lokasi bangunan Groin di Desa Tambaksari

Figure 13. Location of the groin building in Tanjungpakis village

\section{d. Desa Tanjungpakis}

Gelombang yang datang ke pantai ini berasal dari Timur Laut dan Timur dimana arah nya tegak lurus pantai serta kondisi batimetri yang landai dan garis pantai yang beruabah akibat abrasi maka bangunan pelindung yang cocok adalah bangunan Breakwater.

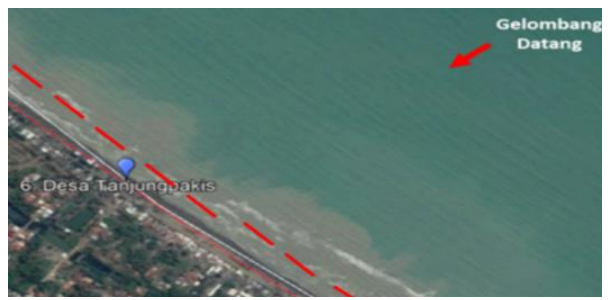

Gambar 14. Lokasi bangunan Breakwater di Desa Tanjungpakis

Figure 14. Location of the Breakwater building in Tanjungpakis village

\section{BAHASAN}

Dalam penentuan alternatif bangunan pantai dapat dilakukan dengan mempertimbangkan berbagai faktor, antara lain kondisi hidro-oseanografi di pantai tersebut, penyebab terjadinya abrasi dan tujuan yang akan dicapai serta 
pengaruh terhadap lingkungan. Menurut Widhianto et al. (2015), pemilihan bangunan pantai ditentukan oleh berbagai aspek, antara lain kesesuaian terhadap batimetri, arah gelombang dominan, kesesuaian orientasi dengan arah arus dominan, sedimentasi, pengamanan permukiman penduduk, ruang untuk kegiatan pariwisata, gangguan terhadap pemandangan, ruang untuk kehidupan biota laut, kemudahan memperoleh bahan material yang digunakan, dan kemudahan pelaksanaan pembangunan.

Kajian penilaian terhadap aspek penentuan alternatif bangunan pantai tersebut dianalisa dengan menggunakan data primer dan data sekunder, kemudian disesuaikan terhadap 6 titik lokasi kajian untuk menyimpulkan struktur bangunan pantai mana yang sesuai sebagai bangunan pengaman pantai. Dalam kajian ini, dari beberapa aspek tersebut ada yang datanya berdasarkan data primer yaitu pengambilan data serta pengamatan kondisi lapangan dan data sekunder yaitu data yang sudah ada sebelumnnya, kemudian diolah untuk memperoleh model data yang diperlukan.

Data primer merupakan pengambilan data langsung ke lokasi penelitian dengan melakukan pengukuran paramemeter hidro oseanografi seperti kedalaman dan tinggi gelombang di beberapa titik disekitar pantai yang diperlukan untuk pemodelan garis pantai dan gelombang, serta pengambilan data topografi dan gambar disekitar pantai untuk melihat kondisi abrasi dan sedimentasi, juga melakukan wawancara dengan beberapa penduduk setempat. Data sekunder adalah data yang diperoleh dari berbagai sumber, seperti data topografi, batimetri, data pasang surut dan data angin. Data topografi, batimetri dan pasang surut diperoleh dari Badan Informasi Geospasial (BIG, 2019). Data angin diperoleh dari ECMWF (European Centre for Medium-Range Weather Forecasts) pada lokasi sekitar perairan laut Jawa sedangkan data gelombang yang diperoleh adalah prediksi gelombang dengan melakukan pengolahan data angin.

Hasil pengambilan data batimetri dan pengolahan data dengan perangkat lunak GENESIS - CEDAS (Coastal Engineering Design \& Analysis System), diperoleh variasi kedalaman di sekitar garis pantai Kabupaten Karawang (garis putih) yaitu antara -5 sampai dengan -17 meter, artinya kondisi batimetri di pantai Karawang cenderung landai.

Berdasarkan distribution of wind frequency dan waverose untuk tinggi gelombang selama 10 tahun, didapatkan dominansi gelombang di lokasi kajian dari arah Timur dengan range antara $30 \mathrm{~cm}$ s.d. lebih dari $150 \mathrm{~cm}$. Arah dan tinggi gelombang pada lokasi penelitian didominansi yaitu dari arah Timur $(25 \%)$ serta Barat Laut (10\%). Tinggi Gelombang pada lokasi penelitian berkisar rata-rata $0.98 \mathrm{~m}$, dimana kejadian gelombang terbesar dari arah Timur dan Barat Laut.

Dari pengambaran gelombang di peta lokasi penelitian terlihat bahwa arah datang gelombang yaitu dari Timur Laut dan Timur menghantam lokasi dari daerah lokasi penelitian yaitu 6 pantai pada lokasi penelitian yang tersebar pada garis pantai Kabupaten Karawang. Arah gelombang baik dari Timur Laut maupun dari Timur memang tidak secara tegak lurus, artinya pada beberapa lokasi bisa terjadi abrasi dan juga deposisi (pembentukan sedimen baru). Menurut Pasaribu et al. (2017, 2019), kondisi ini sesuai dengan penelitian yang dilakukan sebelumnya mengenai indentifikasi kerusakan pantai di kabupaten Karawang bahwa sebagian daerah pantai Karawang mengalami abrasi dan sebagian lagi mengalami sedimentasi.

Dengan melihat arah datangnya gelombang, tinggi gelombang serta kondisi batimetri dan topografi pantai maka dapat ditentukan jenis dari bangunan pantai yang akan digunakan sebagai bangunan pengaman pantai. Penggambaran posisi dan bentuk dari bangunan pantai tersebut dilokasi 
penelitian dilakukan dengan mengunakan perangkat lunak CEDAS (Coastal Engineering Design \& Analysis System).

Berdasarkan analisa model gelombang dan melihat kondisi batimetri, topografi serta aspek lingkungan pantai, maka bangunan pengaman pantai yang sesuai dengan kondisi pantai Karawang adalah breakwater dan groin. Menurut Triatmodjo $\quad(1999,2012)$, bangunan breakwater dan groin ini dapat mengurangi limpasan gelombang yang menuju pantai, sehingga dapat melindungi pantai dari gempuran gelombang.

Jenis bangunan pengaman pantai yang sesuai untuk desa Pusakajaya Utara dan desa Tanjungpakis adalah breakwater sedangkan bangunan pantai yang sesuai untuk desa Sukajaya, desa Sedari dan desa Tambaksari adalah groin. Untuk desa Muara Cilamaya disarankan membangun jetty karena ada muara sungai disekitarnya.

\section{SIMPULAN}

1) Batimetri pantai Kabupaten Karawang mempunyai variasi kedalaman di sekitar garis pantai yaitu antara -5 sampai dengan -17 meter, artinya kondisi batimetri di pantai Karawang cenderung landai.

2) Tinggi gelombang di pantai Karawang dominasi gelombang dari arah Timur dengan tinggi gelombang antara $30 \mathrm{~cm}$ sampai dengan lebih dari $150 \mathrm{~cm}$, sedangkan pada lokasi penelitian tinggi gelombang berkisar rata-rata $0.98 \mathrm{~m}$, dimana kejadian gelombang terbesar berasal dari arah Timur dan Barat Laut.

3) Pantai di Kabupaten Karawang telah mengalami kerusakan akibat abrasi sehingga perlu dibangun breakwater dan groin agar kerusakan pantai tidak semakin besar dan menimbulkan kerugian yang signifikan.

4) Bangunan pengaman pantai berupa breakwater sesuai untuk Desa Pusakajaya Utara dan Desa
Tanjungpakis, sedangkan bangunan groin sesuai untuk kawasan Desa Sukajaya, Desa Sedari dan Desa Tambaksari.

\section{DAFTAR PUSTAKA}

Agus, F., Soeprijadi, L., \& Pasaribu, R. P. (2020). Kajian Hidro-Oseanografi di Perairan Kabupaten Karawang. PELAGICUS, 1(1), 39-51.

[BIG] Badan Informasi Geospasial. (2019). Data Online Pasang Surut. Diakses pada: http://tides.big.go.id/pasut/.

[CERC] Coastal Engineering Reserch Center. (1984). Shore Protection Manual Volume I. Washington: US Army Coastal Engineering Research Center.

[CERC] Coastal Engineering Reserch Center. (2002). Engineering and Design Coastal Engineering Manuals. Washington: US Army Coastal Engineering Research Center.

Hariyadi. (2011). Analisis Perubahan Garis Pantai selama 10 Tahun Menggunakan CEDAS (Coastal Engineering Design and Analisys System) di Perairan Teluk Awur pada Skenario Penambahan Bangunan Pelindung Pantai. Buletin Oseanografi Marina, 1, 82-94.

Irwan, A. (2019). Analisis Abrasi Pantai Pada Akses Jalan BahumbeluMorowali Sulawesi Tengah. Journal of Applied Science (JAPPS), 1(2), 19.

Pratikto, W. A., Suntoyo, Solikhin, Sambodho, K. (2014). Struktur Pelindung Pantai. Jakarta: PT. Mediatama Saptakarya.

Pasaribu, R., Agus, F., Tanjung, A., \& Amdani. (2017). Indentifikasi Kerusakkan Pantai di Kabupaten Karawang. Jurnal STP-Teknologi dan Penelitian Terapan, 20 (2), 185199. 
Pasaribu, R., Agus, F., \& Soeprijadi, L. (2019). Spatial Analysis of Coastline Change by Remote Sensing in the North Coast of Karawang Regency. Jurnal Geografi Lingkungan Tropik, 3(2), 50-56.

Pasaribu, R., Soeprijadi, L., \& Sutono, D. (2019). Kajian Abrasi dan Sedimentasi dengan Teknologi Remote Sensing di Pantai
Karawang. Jurnal Airaha, 8(02), 137-147.

Triatmodjo, B. (1999). Teknik Pantai. Yogyakarta: Beta Offset.

Triatmodjo, B. (2012). Perencanaan Bangunan Pantai. Yogyakarta: Beta Offset.

Widhianto, S. L., Kharisma, D., Suharyanto, S., \& Hardiyati, S. (2015). Kajian Struktur Pengaman Pantai Sigandu, Batang. Jurnal Karya Teknik Sipil, 3(4), 1207-1221. 